\title{
Landscape-Level And Stand-Level Factors Play Diverse Roles During Different Periods of Dendroctonus Valens Invasion In North China
}

\section{Zhongyi Zhan ( $\sim 18600508400 @ 163 . c o m$ )}

Beijing Forestry University https://orcid.org/0000-0002-1443-573X

Lili Ren

Beijing Forestry University

Linfeng Yu

Beijing Forestry University

Zhiwen Guo

Beijing Forestry University

Yujie Liu

Beijing Forestry University

Haonan Li

Beijing Forestry University

Lixia Wang

Beijing Forestry University

Youqing Luo

Beijing Forestry University

\section{Research Article}

Keywords: Red turpentine beetle, stand scale, landscape scale, different periods of invasion

Posted Date: June 14th, 2021

DOI: https://doi.org/10.21203/rs.3.rs-552950/v1

License: (1) (1) This work is licensed under a Creative Commons Attribution 4.0 International License. Read Full License 


\section{Abstract}

In recent years, the red turpentine beetle (RTB), an invasive pest species, has caused extensive pine mortality in North China. Although some studies have theoretically clarified the interference mechanism of multi-level factors with the development of RTB damage, knowledge about this mechanism from the empirical research is still limited. The aim of this study was to determine whether the primary factors influencing RTB occurrence change during different periods of RTB invasion. Stand-level variables of sample plots were obtained through field investigation and the forest resource survey data including forest stand characteristics, topographic characteristics, and soil properties. Remote sensing classified images were to develop the characteristic variables related to landscape composition and configuration around the sample plots at multiple scales. Generalized linear models (GLMs) and generalized linear mixed models (GLMMs) were used to explore the relative importance of stand-level and landscape-level variables in explaining the severity of RTB damage. Result showed that two stand-level factors, aspect and canopy density, were the best predictors of damage in the early stage of RTB invasion. The landscape-level factor, the proportion of Chinese pine (Pinus tabuliformis) patches, was the main predictor of damage in the middle stage of RTB invasion. The most effective spatial scale at which RTB responded to landscape pattern was $250 \mathrm{~m}$. With the increasing severity of RTB damage, the factors driving RTB invasion have shifted from the stand-level to the landscape-level. This calls for an urgent consideration of multi-scale processes to address the changing disturbance regimes in ecosystem management.

\section{Key Message}

- Dendroctonus valens is an invasive pest species caused extensive pine mortality in North China

- No study verified the impact of multi-level factors on bark beetle damage at different stages of outbreak.

- The stand-level factors (canopy density and aspect) had more influence on RTB occurrence in the early stage

- The landscape-level factor (host availability) was a more important predictor in the middle stage of RTB outbreak

- Forestry management of RTB outbreak should depend on knowledge combined from multiple spatial scales, from the stand scale to the landscape scale

\section{Introduction}

Red turpentine beetle (RTB), Dendroctonus valens (Coleoptera: Curculionidae: Scolytinae), an invasive pest introduced from North America, is an important natural disturbance agent of forest ecosystems across a wide range of landscapes in China (Qiu, 2013; Sun et al., 2012; Yan et al., 2005). In 1998, RTB invaded Shanxi Province for the first time. In the following years, RTB spread rapidly from Shanxi Province to the adjacent provinces, causing the mortality of a large amount of Chinese pine (Pinus 
tabuliformis) trees and developing potential threats to healthy pine forests in North China (Cheng et al., 2015; Yan et al., 2005). In forest ecosystems, the outbreak of bark beetles has significant ecological effects on forest succession, fuel dynamics, nitrogen and carbon cycling, as well as substantial socioeconomic impacts (Abbott et al., 2009; Kurz et al., 2008). Considering the wide host range and spatial distribution of RTB, many geographic areas are at risk of being invaded, such as Eurasia, which has abundant suitable pine hosts (Erbilgin et al., 2007).

During the incipient stage of an outbreak, weakened or diseased pines are more likely to be selected by bark beetles (Raffa et al., 2008). Once they reach high population levels due to warm climatic conditions and availability of hosts, selective pressure declines as higher densities facilitate successful attack on more vigorous trees (Boone et al., 2011; Jones et al., 2019). In the process of the bark beetle populations from endemic to epidemic, stand- and landscape-level factors can influence the amount and distribution of tree mortality caused by bark beetles, leading to beetle-killed forest stands across the landscape (Gilbert et al., 2005; Ogris \& Jurc, 2010; Raffa et al., 2008; Seidl et al., 2015; Thom et al., 2013). Understanding the multi-scale factors that are associated with increased severity of RTB outbreak is critical to predict future patterns of forest structure, function and composition, and socioeconomic impacts. However, the multi-scale factors driving RTB damage have rarely been studied.

Stand-level characteristics can directly or indirectly impact bark beetles and the vitality of their hosts, thereby influencing the stand susceptibility to bark beetles. Previous studies explored the effects of forest stand characteristics (Ml et al., 2012; Netherer \& Nopp-Mayr, 2005; Pasztor et al., 2014), topographical characteristics, (Akkuzu et al., 2009; Mezei et al., 2014; Walter \& Platt, 2013), and soil properties (Dutilleul et al., 2000; Simard et al., 2012) on bark beetle damage. Since the observation of the selective behavior of bark beetles at the stand scale is limited for understanding the outbreak, an examination of beetle interactions at a landscape scale would be necessary (Nelson et al., 2006; Robertson et al., 2008). Landscape composition (i.e., the proportion and diversity of the cover types) and configuration (i.e., the spatial arrangement of the cover types such as the shape and connectivity of patches of a given category) can affect the spread of insect defoliator outbreaks (Balzan et al., 2016; Dominik et al., 2018). This is particularly true for bark beetles, which interact with their tree hosts across multiple spatial scales (Raffa et al., 2008).

Boone et al. (2011) have highlighted the need for additional attention to research on the different phases of forest pest outbreaks. Landscape- and stand-level factors may have different effects on the potential locations of beetle attack during different periods of outbreaks. For example, stand-level factors may be important to explain the onset of local eruptions, while landscape-level factors are possibly more important once a regional outbreak has begun (Raffa et al., 2008; Simard et al., 2012). However, the mechanistic underpinnings whether stand- and landscape-level factors play different roles in different stages of bark beetle outbreak are scarce. As far as we know, no suitable data in the published studies can be utilized to explore the impact of landscape-level factors on bark beetle attack in the initial stage of an infestation, as the tree mortality has been massive and continuous at the landscape scale (Seidl et al., 
2015; Simard et al., 2012). The aim of this study was to close this gap, which distinguished the initial conditions leading to an outbreak and the factors facilitating the spread.

In recent years, along the distribution of pine forests, RTB has spread to Inner Mongolia and Liaoning Province of China (Tao et al., 2019). Here we carried out the experiments in the Heilihe area of Inner Mongolia and the Dahebei area of Liaoning Province. Due to the different introduction times, the degree of RTB damage was different between these two areas (Fig. 1). The purpose of this study was to identify key stand- and landscape-level factors influencing RTB invasion in different stages. We hypothesized that: (1) stand-level factors would be more important in the initial stage of RTB invasion; and (2) the role of landscape-level factors would be more vital in the middle stage of RTB invasion. In addition, we explored the optimal scale to predict RTB occurrence at three spatial scales $(250,500$, and $1000 \mathrm{~m})$. In addition, we explored the optimal scale to predict RTB occurrence at three spatial scales $(250,500$, and $1000 \mathrm{~m}$ ). Such result would enable us to work at the most effective spatial scale (Jackson \& Fahrig, 2012).

\section{Material And Methods}

\section{Study areas}

This study was conducted in two areas: the Heilihe town of Inner Mongolia and the Dahebei town of Liaoning Province (Fig. 1). Due to the different introduction times of RTB from Shanxi Province to the above two regions, the initial occurrence times of RTB in the Dahebei area and Heilihe area were 2014 and 2017, respectively. According to the unmanned aerial vehicle (UAV) data of these two areas and the four grading criteria proposed by White et al. (2005), the Heilihe area was determined to be in the early stage of RTB outbreak with $1 \%-5 \%$ trees having a red crown, while the Dahebei area was in the middle stage of RTB outbreak with $5 \%-20 \%$ of trees showing a red crown.

The Heilihe town covers approximately $531 \mathrm{~km}^{2}$, rising from $750 \mathrm{~m}$ to $1200 \mathrm{~m}$ above sea level. The mean annual precipitation and temperature of this area are $470 \mathrm{~mm}$ and $6{ }^{\circ} \mathrm{C}$, respectively (Heilihe Forestry Station). The Dahebei town covers an area of $176 \mathrm{~km}^{2}$ and its elevation ranges from 428 to 1018 $\mathrm{m}$ above sea level. Similarly, the mean annual precipitation and temperature of this area are $450.9 \mathrm{~mm}$ and $8.6^{\circ} \mathrm{C}$, respectively (China Meteorological Data Service Center, 2021). The two areas are dominated by Chinese pine pure forests. Besides, larch (Larix principis-rupprechtii) (not a host tree of RTB) and some broad-leaved tree species also grow in the study areas. The remaining landscapes are characterized as grasslands, agricultural lands, and urban areas.

\section{Stand selection and field sampling}

\section{Area in the early stage of RTB invasion}

Once forest stands are attacked by RTB, indicators such as pitch tubes and boring materials can be used to inspect whether the trees have been infected. In early August of 2018 and 2019, 79 sample plots (30 m 
$\times 30 \mathrm{~m}$ ), in which the trees showed a continuum of damage degree caused by RTB, were randomly selected in the study area (Fig. 2). The sample plots were located at least $500 \mathrm{~m}$ from each other to reduce spatial autocorrelation of landscape elements. The coordinates of these sample plots were recorded using a GPS receiver (Garmin eTrex 309x, Beijing, China) with a precision of $<3 \mathrm{~m}$. In each sample plot, we recorded the diameter at breast height (DBH), species name, and status (infected or uninfected) for each tree with a $\mathrm{DBH}>8 \mathrm{~cm}$. We used the canopy projection method to calculate canopy closure (Bunnell \& Vales, 2011). Mineral soil (20 cm depth) was collected and composited at the center and four corners of the sample plots. Then, soil organic matter and total nitrogen contents were calculated by the potassium dichromate oxidation and Kjeldahl methods, respectively (Bao \& Jiang, 2013). As for topographical characteristics, we recorded the elevation, slope, and aspect for each sample plot. In the subsequent data processing, we transformed the aspect to a south-west-ness index to express the stand environment in sun exposure or dryness (Beers et al., 1966). We recorded the number of RTB entrance holes in the sample plots to represent the damage degree, which was used as the response variable in model construction statistics.

\section{Area in the middle stage of RTB outbreak}

In September 2018, we observed that all of the stands in the Dahebei research area were suffered largescale RTB outbreak through field investigation. The damage in the middle stage of RTB outbreak can be directly detected using UAV images. Therefore, we used the DJI Inspire 2 drone (DJI, Shenzhen, China) to collect RGB images of the whole stand. We obtained 24 synthetic UAV images, each covering more than 20 hectares. We delineated $32(30 \mathrm{~m} \times 30 \mathrm{~m})$ sample plots (Fig. 2$)$ on UAV images and the distance between the sample plots was more than $500 \mathrm{~m}$ as mentioned earlier.

The mean DBH and canopy density of the sample plots were obtained from the National Forest Resources Intelligent Management Platform (2021) and corresponding UAV images. We used digital elevation model (DEM) (Aster GDEM 30 m resolution, 2021) to obtain the elevation, aspect, and slope data of the sample plots. We counted the numbers of damaged Chinese pines (yellow, red, and grey crowns in UAV images) in these sample plots to represent different degrees of RTB damage and took them as the response variable for areas in the middle stage of RTB outbreak.

The plots showing different stages of RTB outbreak were selected from areas without external interferences, such as fire and pest management that can promote or inhibit the occurrence of bark beetles (Agne et al., 2016; Mezei et al., 2017). The variables related to the stand characteristics, topographical characteristics, and soil properties of sample plots were treated as stand-level variables (Mezei et al., 2014). In addition, through remote sensing imagery of Gaofen-2 (China Centre for Resources Satellite Data and Application, 2020) and field investigation, the forest coverage of the buffer with a radius of $1000 \mathrm{~m}$ around the sample plots ranges from $10 \%$ to $75 \%$ to ensure a reasonable distribution of the landscape-level variables (Wang et al., 2019).

\section{Landscape-level variables}


We selected the landscape metrics that are most likely to affect the bark beetle outbreak according to the previous studies (Bone et al., 2013; Simard et al., 2012; Wang et al., 2019). We measured landscape composition using the proportion of Chinese pines (PLAND) and Shannon's diversity index (SHDI) calculated from all land cover types. We used mean shape index (SHAPE_MN) and cohesion index (COHESION) to quantify landscape configuration.

Landscape-level variables were quantified in the area around each sample plot at three radii $(250,500$, and $1000 \mathrm{~m}$ ) based on high-resolution remote sensing imagery, which were acquired from the Gaofen-2 satellite covering all study areas in September 2017 and June 2018. Land cover types were classified into five categories: Chinese pines, larches, broad-leaved trees, grasslands, farmlands, and residence communities. Additional details such as the classification method and map of the remote sensing images are available in Supporting Information (Fig S1, Table S1)

\section{Model selection}

Prior to model selection, we measured multicollinearity among all variables, and COHESION and soil organic matter were removed (see methods in Supplementary S2). The final set of variables is listed in Table 1. Next, to evaluate the response of RTB outbreak to stand- and landscape-level variables, we constructed generalized linear mixed models (GLMMs) for the area in the early stage of RTB outbreak and generalized linear models (GLMs) for the area in the middle stage of RTB outbreak. The year was used as random effect. Since overdispersion was observed in our data, we used a negative binomial error distribution that would provide better parameter estimates than the Poisson distribution (Militino, 2010).

Models were ranked based on corrected Akaike's information criterion (AICC) adjusted for small-sized samples (Krasnov et al., 2019). We selected the top model set with a $\Delta \mathrm{AICc}$ (i.e., AICc - $\left.A \mathrm{AlC}_{\min }\right)<2$, which is considered as effective. Model averaging was performed to produce Akaike weights $(\omega)$ and modelaveraged partial regression coefficients for each variable. The relative importance value of each variable was quantified by the sum of the Akaike weights for each model in which the variable appeared. To approximate a normal distribution and enhance model stability, variables were $\log (x+1)$-transformed as needed prior to model fitting (Schmiedel et al., 2015). Finally, we calculated the $\mathrm{R}^{2}$ of the best model (with the minimum AlCc value) to observe the goodness of fit.

Variables found to be the most important in the early and middle stages of RTB outbreak (aspect, canopy density, and PLAND) were grouped if they were in the same direction (for aspect) or at equidistant intervals (for canopy density and PLAND), and a nonparametric Kruskal-Wallis test with post hoc was conducted for each variable. While the model located the variables that significantly affected RTB outbreak, the purpose of this analysis was to elucidate which groups of variables differed from the others, and to help forest managers effectively monitor and control RTB outbreak. All statistical analyses were performed in the R statistical programming environment (R Core Team, 2020) including the packages arm (Gelman, 2008), Ime4 (Krasnov et al., 2019), MuMIn (Bartoń, 2019; Lukacs et al., 2009), piecewiseSEM (Nakagawa et al., 2017), and glmmTMB (Brooks et al., 2017). 
Table 1 List of explanatory variables used in model analysis of areas in different stages of RTB invasion

\begin{tabular}{|c|c|c|c|c|c|}
\hline \multirow{2}{*}{$\begin{array}{l}\text { Variable } \\
\text { category }\end{array}$} & \multirow[t]{2}{*}{ Variable } & \multirow{2}{*}{$\begin{array}{l}\text { Scale of } \\
\text { measurement }\end{array}$} & \multicolumn{2}{|l|}{ Data source } & \multirow{2}{*}{$\begin{array}{l}\text { Variable } \\
\text { description }\end{array}$} \\
\hline & & & $\begin{array}{l}\text { Area in the early } \\
\text { stage of RTB } \\
\text { outbreak }\end{array}$ & $\begin{array}{l}\text { Area in the } \\
\text { middle stage of } \\
\text { RTB outbreak }\end{array}$ & \\
\hline \multirow[t]{6}{*}{$\begin{array}{l}\text { Stand-level } \\
\text { factors }\end{array}$} & $\mathrm{DBH}(\mathrm{cm})$ & Stand & $\mathrm{FI}$ & NFRD & $\begin{array}{l}\text { Stand mean } \\
\text { DBH }\end{array}$ \\
\hline & $\begin{array}{l}\text { Canopy } \\
\text { density (\%) }\end{array}$ & Stand & $\mathrm{FI}$ & NFRD & $\begin{array}{l}\text { Degree of } \\
\text { canopy } \\
\text { closure }\end{array}$ \\
\hline & Slope $\left(^{\circ}\right)$ & Stand & $\mathrm{FI}$ & DEM $30 \mathrm{~m}$ & Relief slope \\
\hline & Aspect $\left({ }^{\circ}\right)$ & Stand & $\mathrm{FI}$ & DEM $30 \mathrm{~m}$ & $\begin{array}{l}\text { Stand } \\
\text { orientation }\end{array}$ \\
\hline & $\begin{array}{l}\text { Elevation } \\
(\mathrm{m})\end{array}$ & Stand & $\mathrm{FI}$ & DEM $30 \mathrm{~m}$ & $\begin{array}{l}\text { Stand } \\
\text { elevation }\end{array}$ \\
\hline & $\begin{array}{l}\text { Total N } \\
(\mathrm{g} / \mathrm{kg})\end{array}$ & Stand & LM & - & $\begin{array}{l}\text { Total nitrogen } \\
\text { of soil }\end{array}$ \\
\hline \multirow[t]{3}{*}{$\begin{array}{l}\text { Landscape- } \\
\text { level } \\
\text { factors }\end{array}$} & SHAPE_MN & Landscape & FC & FC & $\begin{array}{l}\text { Shape } \\
\text { complexity of } \\
\text { host patches }\end{array}$ \\
\hline & PLAND & Landscape & FC & $\mathrm{FC}$ & $\begin{array}{l}\text { Connectivity } \\
\text { of host } \\
\text { patches }\end{array}$ \\
\hline & SHDI & Landscape & FC & FC & $\begin{array}{l}\text { Diversity of } \\
\text { landscape } \\
\text { types }\end{array}$ \\
\hline
\end{tabular}

FI, field investigation; NFRD, national forest resource; LM, laboratory measurement; FC, forest classification; - means there is no data.

\section{Results}

\section{Relative importance of variables in different invasion stages}

\section{Area in the early stage of RTB outbreak}

The average number of RTB entrance holes in each plot was 20.82 (SE = 3.83). The aspect was the primary driving factor $(P=0.008$; Table 2$)$ affecting the RTB occurrence at both the stand and landscape scales with its relative importance approaching 1 (Fig. 3). The number of RTB entrance holes slowly increased from the northeast to southwest stands (Fig. 4a). Moreover, canopy density (relative importance $=0.96 ; \mathrm{P}=0.031$ ) significantly influenced RTB occurrence (Table 2; Fig. 3 ). The number of RTB entrance holes decreased with the increase of canopy density (Fig. 4b). The landscape-level factor 
SHAPE_MN (shape complexity of host patches) also played a role as its relative importance reached 0.69 (Fig. 3). Moreover, the relative importance of DBH and elevation was also close to 0.5 (Table 2), but these three indicators were not statistically significant in the models. In general, stand-level factors exerted more influence on RTB outbreak in the early stage.

\section{Area in the middle stage of RTB outbreak}

The average number of damaged trees of the 32 plots in the middle stage of RTB outbreak was 12.69 (SE $=2.64$ ). The connectivity of Chinese pine patches (PLAND, $P=0.009$; Table 2 ) significantly affected RTB damage among all the variables with its relative importance approaching 1 (Fig. 3). The exponentially positive correlation between RTB damage and PLAND indicated that with the increasing host patches, stands were more vulnerable to RTB outbreak (Fig. 4c). The remaining variables showed no significant effects on RTB occurrence, with the relative importance values around 0.15. Compared with the standlevel factors, the landscape-level factors were more predominant in the middle stage of RTB outbreak.

The optimal spatial scales for the two invasion stages at which RTB damage best responded to the independent variables were both defined at $250 \mathrm{~m}$, which had an optimal AICc value (Table 2; the results for $500 \mathrm{~m}$ and $1000 \mathrm{~m}$ are shown in Table S2 and S3).

Table 2 Summary results of the model averaging procedure assessing effects of stand- and landscapelevel factors on RTB damage $($ scale $=250 \mathrm{~m})$. 
Estimate Std. Error z-value P-value AICc $\mathbf{R}^{2}$

\begin{tabular}{|c|c|c|c|c|c|c|}
\hline Early invasion stage & & & & & 624.6 & $0.20(0.23)$ \\
\hline Intercept & 5.89 & 12.12 & 0.48 & 0.630 & & \\
\hline $\mathrm{DBH}$ & -2.68 & 1.55 & 1.70 & 0.089 & & \\
\hline Slope & 1.49 & 1.01 & 1.45 & 0.148 & & \\
\hline Aspect & 0.94 & 0.36 & 2.61 & $0.009 * *$ & & \\
\hline Canopy density & -10.53 & 4.82 & 2.15 & $0.031 *$ & & \\
\hline Elevation & -6.09 & 4.09 & 1.47 & 0.142 & & \\
\hline Total N & 7.07 & 7.00 & 0.99 & 0.321 & & \\
\hline SHAPE_MN & 34.49 & 20.20 & 1.69 & 0.092 & & \\
\hline PLAND & -1.40 & 1.09 & 1.26 & 0.207 & & \\
\hline SHDI & -13.86 & 7.09 & 1.92 & 0.054 & & \\
\hline Middle invasion stage & & & & & 223.8 & 0.26 \\
\hline Intercept & -2.65 & 4.64 & 0.55 & 0.581 & & \\
\hline $\mathrm{DBH}$ & 0.75 & 2.10 & 0.34 & 0.733 & & \\
\hline Slope & 0.47 & 1.00 & 0.45 & 0.651 & & \\
\hline Aspect & 0.18 & 0.26 & 0.67 & 0.502 & & \\
\hline Canopy density & -1.31 & 5.73 & 0.22 & 0.826 & & \\
\hline Elevation & -1.11 & 5.02 & 0.21 & 0.832 & & \\
\hline SHAPE_MN & 7.37 & 6.60 & 1.18 & 0.239 & & \\
\hline PLAND & 2.96 & 1.10 & 2.59 & $0.009 * *$ & & \\
\hline SHDI & -6.08 & 9.85 & 0.59 & 0.554 & & \\
\hline
\end{tabular}

P-values were calculated based on averaged parameter estimates using the top ranked models. * means significance at the 0.05 level and ** means significance at the 0.01 level. The model's $R^{2}$ in the early invasion stage represented marginal $\mathrm{R}^{2}$ (conditional $\mathrm{R}^{2}$ ).

\section{Nonparametric test of important variables}

Based on the results obtained from modeling, we divided significant variables into four groups (Fig. 5a, b, and c). The Kruskal-Wallis test results showed that the number of RTB entrance holes was significantly higher in the sample plots facing south compared with those facing the north and east directions (Fig. 
5a). The number of RTB entrance holes was significantly higher in the stands with canopy density less than $30 \%$ than those with canopy density more than $40 \%$ (Fig. 5b). The number of damaged trees with a proportion of Chinese pines larger than 0.4 was significantly higher than those with a proportion of Chinese pines smaller than $0.4(<0.2$ and $0.2-0.4)$.

\section{Discussion}

\section{Performance of landscape-level and stand-level factors in different stages of RTB outbreak}

Previous studies have shown that bark beetle damage is affected by both beetle pressure and forest susceptibility (Nelson et al., 2006; Raffa et al., 2008). Similar to the studies of Nelson (2006) and Bone (2013), we only considered forest susceptibility (without considering beetle pressure) in our research, which may also be the attribution of the low $\mathrm{R}^{2}$ values obtained from generalized models. The purpose of our study is to explore the role of large-scale factors and small-scale factors in forest susceptibility assessment in different stages of RTB invasion. The results obtained supported our hypothesis that the stand-level factors were more important to predict damage in the early stage of RTB outbreak and the landscape-level factors performed better in predicting damage in the middle stage of RTB outbreak. This is also in line with the conjectures gained from other studies on the spruce bark beetle and the mountain pine beetle, in which the researchers failed to prove their hypotheses due to data constraints (Raffa et al., 2008; Seidl et al., 2015; Simard et al., 2012).

The diverse roles of stand-level and landsacpe-level factors play in the early and middle stages of RTB outbreak may be influenced by the population dynamics of this beetle. The interaction between the attack ability of bark beetles and tree defense determines the success rate of bark beetle colonization and then subsequent reproduction is contingent on the presence of weakened host trees such as burned or felled trees (Raffa et al., 2008; Raffa \& Berryman, 1983). Under endemic conditions, stand-scale attributes, such as tree vigor, size, and canopy density, determine the outcome of bark beetle damage. However, the existence of environment conditions favored by bark beetles, such as drought and wind disturbance, enables a large-scale attack of host trees by bark beetles regardless of their ages or sizes (Raffa et al., 2008). The transition from local- to large-scale outbreak might be influenced by landscape-level factors.

\section{Stand-level factors}

Many studies have revealed a strong positive correlation between DBH and bark beetles' feeding and oviposition (Akkuzu et al., 2009; Amman, 1972; Ml et al., 2012). However, consistent with Lausch et al. (2011), DBH showed no significant influence on bark beetle preferences in our analysis. In the field investigation, we also found RTB-damaged Chinese pine trees with both large and small DBH values. Moreover, pines are less vulnerable to RTB attack in mature stands because of their stronger resistance. Netherer and Nopp-Mayr (2005) and Pasztor et al. (2014) have shown that stands with low canopy closure may suffer bark beetle attacks at a higher probability, because the relatively high temperature within stands of low canopy closure is more attractive to bark beetles. Our research also 
confirmed this result, RTB preferred to invade the forest stand with a low canopy density, which was an important predictive variable in the early stage of RTB outbreak.

Previous studies (Lausch et al., 2011; Logan \& Powell, 2001; Mezei et al., 2014) have shown that elevation plays an important role in the early stage of bark beetle occurrence, because the low temperature accompanying high-altitude stands could slow down the development of larvae, thus reducing the generation number of bark beetles. However, in the subsequent phases, elevation plays a minor role because the long-term damage leads to the lack of host resources in low-altitude areas. The range of activities of bark beetles gradually shifts to high-altitude areas (Gregory et al., 2017). In our analysis, elevation exhibited no significant effect on RTB outbreak in neither stage, which may possibly be attributed to the relatively small range of elevations in our study areas. Similar to the results from Simard et al. (2012), slope and aspect had no effect on RTB damage during the outbreak period. However, we found that aspect was the most important predictor of the model in the early stage of RTB outbreak (Fig. 3) and south-facing stands showed a higher degree of RTB damage compared to stands facing other directions. The susceptibility of south-facing stands may increase because higher levels of solar radiation may reduce tree vitality and enhance beetle survival (Coops et al., 2006). Slope had a weak impact on RTB damage in the early stage of the outbreak, most likely due to the uneven distribution of the field sampling data. There were fewer sampling points on the steep slope due to topographic limits, which also highlighted the importance of sampling in field experiments.

Soil total nitrogen also has a good predictive effect on spruce beetle damage during the outbreak period (Simard et al., 2012). Unfortunately, we failed to obtain soil data for the area in the middle stage of RTB outbreak. Nevertheless, we speculated that the soil properties may have little effect on RTB occurrence because the two study areas were dominated by the same soil type; this speculation was also supported by the model fitting results from areas in the early stage of RTB invasion. In addition, the effect of soil properties on bark beetles only indirectly affects the preference of bark beetles by influencing the growth of vegetation (Reynolds \& Holsten, 1994). Better predictors should focus on the growth of trees or the factors that affect the population dynamics of bark beetles.

\section{Landscape-level factors}

Most of the studies have explored the impact of landscape-level factors on bark beetle damage in the initial and outbreak stages but ignored the middle stage prior to the outbreak (Bone et al., 2013; Seidl et al., 2015; Simard et al., 2012). Our research closed this gap and discovered that landscape-level factors could play a role in the middle stage of RTB outbreak. Walter and Platt (2013) used multi-temporal satellite images to monitor the red attack stage of mountain pine beetle. They revealed that the availability of host trees has an important impact on epidemic spread. Bone et al. (2013) showed that contiguous forests experienced greater tree mortality caused by mountain pine beetles when their populations reached epidemic levels. The outbreak curve of the Ips typographus population is closely related to the connectivity of host patches, which is a key driver of the observed area (Seidl et al., 2015). Although the connectivity of Chinese pine patches (COHESION) was excluded from our analysis, it has a 
high positive correlation with the proportion of Chinese pines (PLAND; Fig S2 and S3). These findings are consistent with our results that the proportion of host patches significantly affected the damage degree in the middle stage of RTB outbreak.

The variable SHAPE_MN didn't show a significant effect on RTB damage in the early stage. However, we revealed through our field survey that RTB preferred trees located at forest edges that are exposed to solar radiation. This edge effect may explain the importance of the shape complexity of host patches (Kautz et al., 2013). Hansen et al. (2016) reported that the spruce bark beetle outbreak was smaller in extent and duration in the landscape with the mixed forest of white spruce and beetle-resistant black spruce compared with homogeneous stands of white spruce. This finding contrasts with our study in which we showed that the Shannon's diversity index describing landscape composition had no significant effect on the damage degree of RTB outbreak in the two study areas. The reason may be that the main host tree species in our study areas is $P$. tabuliformis, while other types of ground objects, such as broad-leaved trees and cultivated lands, distributing in the periphery of host stands don't affect the transmission of RTB in forest stands. This also indicates the necessity to conduct additional experiments to explore the impact of tree diversity on RTB outbreak (Castagneyrol et al., 2013).

The most effective spatial scale at which bark beetles respond to landscape pattern is primarily driven by their dispersal ability (Jones et al., 2019). Simard et al. (2012) found that $500 \mathrm{~m}$ was the most effective measure among four landscape scales during the outbreak period of bark beetles, which is different from that obtained from our study $(250 \mathrm{~m})$. This also indicated that the damage severity of bark beetles gradually developed from the middle stage of occurrence to the outbreak period at the landscape scale. With the aggravation of damage, the effective landscape scale of bark beetles may be more than $500 \mathrm{~m}$, leading to a wider range of host trees to be damaged. The ability to predict landscape scale effects will enable more effective landscape research and help landscape managers carry out pest control practices at an appropriate scale.

In conclusion, we revealed that the stand-level factors (canopy density and aspect) had more influence on RTB occurrence in the early stage, while the landscape-level factor (host availability) was a more important predictor in the middle stage of RTB outbreak. This is well in line with the findings of the disturbance regimes of other beetles (Raffa et al., 2008; Seidl et al., 2015; Simard et al., 2012). In particular, we found that the landscape-level indicators could play a role in the middle stage of RTB occurrence before the final outbreak, which also highlighted the limitation of stand-scale managements, such as the application of traps and pharmacotherapy, during the population growth period of RTB. Forestry management of RTB outbreak should depend on knowledge combined from multiple spatial scales, from the stand scale to the landscape scale. In addition, our research also demonstrated that the UAV-based remote sensing technique has some advantages in the epidemiological study of RTB, which can replace the traditional field survey that is time-consuming and labor-intensive (Zhan et al., 2020).

\section{Declarations}




\section{Authors' contribution}

Zhongyi Zhan conceived and designed research. Zhongyi Zhan and Haonan Li conducted experiments. Zhongyi Zhan analyzed data and wrote the manuscript. All authors participated in review and revision of the manuscript.

Funding This study was supported by the National Key Research \& Development Program of China "Research on key technologies for prevention and control of major disasters in plantation" (2018YFD0600200) and the National Natural Science Foundation of China (31870642).

Acknowledgements We would like to thank the Heilihe National Nature Reserve and the Dahebei Forest Farm for supporting the field experiments and data collection. We are grateful for Dr. Bingtao Gao and for Dr. Yizhou Liu for their help in the field investigation. We appreciate the linguistic assistance provided by TopEdit during preparation of this manuscript.

Conflict of interest Authors declare no competing financial interests.

Ethical approval This article does not contain any studies with human participants or animals performed by any of the authors.

\section{References}

1. Abbott B, Stennes B, Kooten G (2009). Mountain Pine Beetle, Global Markets and the British Columbia Forest Economy. Can J For Res 39:1313-1321. https://doi.org/10.1139/X09-049

2. Agne MC, Woolley T, Fitzgerald S (2016). Fire severity and cumulative disturbance effects in the postmountain pine beetle lodgepole pine forests of the Pole Creek Fire. For Ecol Manage 366:7386. https://doi.org/10.1016/j.foreco.2016.02.004

3. Akkuzu E, Sariyildiz T, küçük M. et al (2009). Ips typographus (L.) and Thanasimus formicarius (L.) populations influenced by aspect and slope position in Artvin-Hatila valley national park, Turkey. Afr J Biotechnol 8:877-882.

4. Amman GD (1972). Mountain Pine Beetle1 Brood Production in Relation to Thickness of Lodgepole Pine Phloem2. J Econ Entomol 65:138-140. https://doi.org/10.1093/jee/65.1.138

5. Aster GDEM 30 m resolution (2021). Geospatial Data Cloud. http://www.gscloud.cn/sources/index? pid=302. Accessed 1 April 2021

6. Balzan MV, Bocci G, Moonen AC (2016). Landscape complexity and field margin vegetation diversity enhance natural enemies and reduce herbivory by Lepidoptera pests on tomato crop. BioControl 61:141-154. https://doi.org/10.1007/s10526-015-9711-2

7. Bao SD, Jiang RF (2013) Determination of soil organic matter and total nitrogen. In Bao SD (ed), Soil agrochemical analysis. China Agricultural press, Beijing, pp 30-48:

8. Bartoń K (2019). MuMIn: Multi-Model Inference. R package version 1.43.6. http://CRAN.Rproject.org/package=MuMIn 
9. Beers TW, Dress PE, Wensel L (1966). Aspect transformation in site productivity research. J Forest 64:691-692. https://doi.org/10.1093/jof/64.10.691

10. Bone C, White J, Wulder M et al (2013). Impact of Forest Fragmentation on Patterns of Mountain Pine Beetle-Caused Tree Mortality. Forests 4: 279-295. https://doi.org/10.3390/f4020279

11. Boone C, Aukema B, Bohlmann J et al (2011). Efficacy of tree defense physiology varies with bark beetle population density: A basis for positive feedback in eruptive species. Can J For Res 41:11741188. https://doi.org/10.1139/X11-041

12. Brooks ME, Kristensen K, Benthem KJ et al (2017). glmmTMB Balances Speed and Flexibility Among Packages for Zero-inflated Generalized Linear Mixed Modeling. R J 9: 378-400. https://doi.org/10.32614/RJ-2017-066

13. Bunnell FL, Vales DJ (2011). Comparison of methods for estimating forest overstory cover: differences among techniques. Can J For Res 20:101-107. https://doi.org/10.1139/x90-014

14. Castagneyrol B, Jactel $H$, Vacher $C$ et al (2013). Effects of plant phylogenetic diversity on herbivory depend on herbivore specialization. J Appl Ecol 51: 134-141. https://doi.org/10.1111/13652664.12175

15. Cheng C, Zhou F, Lu M, Sun J (2015). Inducible pine rosin defense mediates interactions between an invasive insect-fungal complex and newly acquired sympatric fungal associates. Integr Zool 10: 453464. https://doi.org/10.1111/1749-4877.12138

16. China Centre for Resources Satellite Data and Application (2020). http://www.cresda.com/CN/. Accessed 9 June 2020

17. China Meteorological Data Service Center (2021). National Climatic Data Center 1981-2010 annual normals, Lingyuan, Liaoning. http://data.cma.cn/. Accessed 9 January 2021

18. Coops NC, Wulder, MA, White, JC (2006). Integrating remotely sensed and ancillary data sources to characterize a mountain pine beetle infestation. Remote Sens Environ 105: 83-97. https://doi.org/10.1016/j.rse.2006.06.007

19. DeRose RJ, Long J, Ramsey R (2011). Combining dendrochronological data and the disturbance index to assess Engelmann spruce mortality caused by a spruce beetle outbreak in southern Utah, USA. Remote Sens Environ 115:2342-2349. https://doi.org/10.1016/j.rse.2011.04.034

20. Dominik C, Seppelt R, Horgan FG et al (2018). Landscape composition, configuration, and trophic interactions shape arthropod communities in rice agroecosystems. J Appl Ecol 55:2461-2472. https://doi.org/10.1111/1365-2664.13226

21. Dormann CF, Elith J, Bacher S et al (2013). Collinearity: A review of methods to deal with it and a simulation study evaluating their performance. Ecography 36:27-46. https://doi.org/10.1111/j.16000587.2012.07348.x

22. Dutilleul P, Nef L, Frigon D (2000). Assessment of site characteristics as predictors of the vulnerability of Norway spruce (Picea abies Karst.) stands to attack by Ips typographus L. (Col., Scolytidae). J Appl Entomol 124:1-5. https://doi.org/10.1046/j.1439-0418.2000.00440.x 
23. Erbilgin N, Mori SR, Sun J et al (2007). Response to Host Volatiles by Native and Introduced Populations of Dendroctonus valens (Coleoptera: Curculionidae, Scolytinae) in North America and China. J Chem Ecol 33:131-146. https://doi.org/10.1007/s10886-006-9200-2

24. Fahrig L, Baudry J, Brotons L et al (2011). Functional landscape heterogeneity and animal biodiversity in agricultural landscapes. Ecol Lett 14:101-112. https://doi.org/10.1111/j.14610248.2010.01559.x

25. Gelman A (2008). Scaling Regression Inputs by Dividing by Two Standard Deviations. Stat Med 27:2865-2873. https://doi.org/10.1002/sim.3107

26. Gilbert M, Nageleisen LM, Franklin A et al (2005). Post-storm surveys reveal large-scale spatial patterns and influences of site factors, forest structure and diversity in endemic bark-beetle populations. Landscape Ecol 20: 35-49. https://doi.org/10.1007/s10980-004-0465-y

27. Gregory, JS, Marcin B, Neil M, Tomasz ZK et al (2017). Landscape-Level Spruce Mortality Patterns and Topographic Forecasters of Bark Beetle Outbreaks in Managed and Unmanaged Forests of the Tatra Mountains. Pol J Ecol 65: 24-37. https://doi.org/10.3161/15052249PJE2017.65.1.003

28. Hansen W, Chapin FS, Naughton H et al. (2016). Forest-landscape structure mediates effects of a spruce bark beetle (Dendroctonus rufipennis) outbreak on subsequent likelihood of burning in Alaskan boreal forest. Forest Ecol Manag 369:38-46. https://doi.org/10.1016/j.foreco.2016.03.036

29. Jackson H, Fahrig L (2012). What size is a biologically relevant landscape? Landscape Ecol 27:929941. https://doi.org/10.1007/s10980-012-9757-9

30. Jones K, Shegelski V, Marculis, $\mathrm{N}$ et al (2019). Factors influencing dispersal by flight in bark beetles (Coleoptera: Curculionidae: Scolytinae): from genes to landscapes. Can J For Res 49:1024-1041. https://doi.org/10.1139/cjfr-2018-0304

31. Kautz M, Schopf R, Ohser J (2013). Erratum to: The "sun-effect": microclimatic alterations predispose forest edges to bark beetle infestations. Eur J Forest Res 132:453-465. https://doi.org/10.1007/s10342-013-0686-1

32. Krasnov H, Cohen Y, Goldshtein E et al (2019). The effect of local and landscape variables on Mediterranean fruit fly dynamics in citrus orchards utilizing the ecoinformatics approach. J Pest Sci 92:453-463. https://doi.org/10.1007/s10340-018-1023-8

33. Kurz W, Dymond C, Stinson G, Rampley G, et al (2008). Mountain pine beetle and forest carbon feedback to climate change. Nature 452:987-990. https://doi.org/10.1038/nature06777

34. Lausch A, Fahse L, Heurich M (2011). Factors affecting the spatio-temporal dispersion of Ips typographus (L.) in Bavarian Forest National Park: A long-term quantitative landscape-level analysis. Forest Ecol Manag 261:233-245. https://doi.org/10.1016/j.foreco.2010.10.012

35. Logan JA, Powell J (2001). Ghost Forests, Global Warming, and the Mountain Pine Beetle (Coleoptera : Scolytidae). Am Entomol 47: 160-172. https://doi.org/10.1093/ae/47.3.160

36. Lukacs P, Burnham K, Anderson D (2009). Model selection bias and Freedman's paradox. Ann Inst Stat Math 62:117-125. https://doi.org/10.1007/s10463-009-0234-4 
37. Mezei P, Blaženec M, Grodzki W et al (2017). Influence of different forest protection strategies on spruce tree mortality during a bark beetle outbreak. Ann Forest Sci 74:1-12. https://doi.org/10.1007/s13595-017-0663-9

38. Mezei P, Grodzki W, Blazenec M et al (2014). Host and site factors affecting tree mortality caused by the spruce bark beetle (Ips typographus) in mountainous conditions. Forest Ecol Manag 331:196207. https://doi.org/10.1016/j.foreco.2014.07.031

39. Graf ML, Reid ML, Aukema B et al (2012). Association of tree diameter with body size and lipid content of mountain pine beetles. Can Entomol 144:467-477. https://doi.org/10.4039/tce.2012.38

40. Militino AF (2010). Mixed Effects Models and Extensions in Ecology with R. J R Stat Soc A Stat 173:938-939. https://doi.org/10.1111/j.1467-985X.2010.00663_9.x

41. Nakagawa $S$, Johnson PCD, Schielzeth $H$ (2017). The coefficient of determination $R^{2}$ and intra-class correlation coefficient from generalized linear mixed-effects models revisited and expanded. J R Soc Interface, 14:1-11. https://doi.org/10.1101/095851

42. National Forest Resources Intelligent Management Platform (2021). National Forest Resources Woodland Class 2018. http://zhgl.forestry.gov.cn/. Accessed 20 January 2021

43. Nelson T, Boots B, Wulder M et al (2006). Rating the susceptibility of forests to mountain pine beetle infestations: The impact of data. Can J Forest Res 36:2815-2825. https://doi.org/10.1139/x06-163

44. Netherer S, Nopp-Mayr U (2005). Predisposition assessment systems (PAS) as supportive tools in forest management - Rating of site and stand-related hazards of bark beetle infestation in the High Tatra Mountains as an example for system application and verification. Forest Ecol Manag 207: 99107. https://doi.org/10.1016/j.foreco.2004.10.020

45. Ogris N, Jurc M (2010). Sanitary felling of Norway spruce due to spruce bark beetles in Slovenia: A model and projections for various climate change scenarios. Ecol Model 221:290-302. https://doi.org/10.1016/j.ecolmodel.2009.05.015

46. Pasztor F, Matulla C, Rammer W et al (2014). Drivers of the bark beetle disturbance regime in Alpine forests in Austria. Forest Ecol Manag 318:349-358. https://doi.org/10.1016/j.foreco.2014.01.044

47. Qiu J (2013). China battles army of invaders. Nature 503:450-451. https://doi.org/10.1038/503450a

48. R Core Team (2020). R: A Language and environment for statistical computing. R Foundation for Statistical Computing, Vienna, Austria. https://www.R-proje ct.org/

49. Raffa KF, Aukema B, Bentz B et al (2008). Cross-Scale Drivers of Natural Disturbances Prone to Anthropogenic Amplification: The Dynamics of Bark Beetle Eruptions. BioScience 58:501-517. https://doi.org/10.1641/B580607

50. Raffa KF, Berryman AA(1983). The Role of Host Plant Resistance in the Colonization Behavior and Ecology of Bark Beetles (Coleoptera: Scolytidae). Ecol Monogr 53:27-49. https://doi.org/10.2307/1942586 
51. Reynolds KM, Holsten EH (1994). Relative importance of risk factors for spruce beetle outbreaks. Can J Forest Res 24:2089-2095. https://doi.org/10.1139/x94-268

52. Robertson C, Wulder MA, Nelson TA et al (2008). Risk rating for mountain pine beetle infestation of lodgepole pine forests over large areas with ordinal regression modelling. Forest Ecol Manag 256:900-912. https://doi.org/10.1016/j.foreco.2008.05.054

53. Schmiedel I, Bergmeier E, Culmsee H (2015). Plant species richness patterns along a gradient of landscape modification intensity in Lower Saxony, Germany. Landscape Urban Plan 141:41-51. https://doi.org/https://doi.org/10.1016/j.landurbplan.2015.03.009

54. Seidl R, Muller J, Hothorn T et al (2015). Small beetle, large-scale drivers: how regional and landscape factors affect outbreaks of the European spruce bark beetle. J Appl Ecol 53:530-540. https://doi.org/10.1111/1365-2664.12540

55. Simard M, Powell E, Raffa K et al (2012). What explains landscape patterns of tree mortality caused by bark beetle outbreaks in Greater Yellowstone? Global Ecol Biogeogr 21:556-567. https://doi.org/10.2307/23254431

56. Sun J, Lu M, Gillette N et al (2012). Red Turpentine Beetle: Innocuous Native Becomes Invasive Tree Killer in China. Annu rev entomol 58:293. https://doi.org/10.1146/annurev-ento-120811-153624

57. Tao GZ, Cong XW, Liu SS (2019). effctive pre-endanger management and control mechanism and technology scheme for Dendroctonus valens. J Hebei Forest Sci 1:68-70. https://doi.org/10.16449/j.cnki.issn1002-3356.2019.01.021

58. Thom D, Seidl R, Steyrer $G$ et al (2013). Slow and fast drivers of the natural disturbance regime in Central European forest ecosystems. Forest Ecol Manag 307:293-302. https://doi.org/10.1016/j.foreco.2013.07.017

59. Walter JA, Platt RV (2013). Multi-temporal analysis reveals that predictors of mountain pine beetle infestation change during outbreak cycles. Forest Ecol Manag 302:308-318. https://doi.org/10.1016/j.foreco.2013.03.038

60. Wang B, Tian C, Sun J (2019). Effects of landscape complexity and stand factors on arthropod communities in poplar forests. Ecol Evol 9:7143-7156. https://doi.org/10.1002/ece3.5285

61. White JC, Wulder MA, Brooks D et al (2005). Detection of red attack stage mountain pine beetle infestation with high spatial resolution satellite imagery. Remote Sens Environ 96:340-351. https://doi.org/10.1016/j.rse.2005.03.007

62. Yan Z, Sun J, Don 0 et al (2005). The red turpentine beetle, Dendroctonus valens LeConte (Scolytidae): An exotic invasive pest of pine in China. Biodivers Conserv 14:1735-1760. https://doi.org/10.1007/s10531-004-0697-9

63. Zhan Z, Yu L, Li Z et al (2020). Combining GF-2 and Sentinel-2 images to detect tree mortality caused by red turpentine beetle during the early outbreak stage in North China. Forests 11:172. https://doi.org/10.3390/f11020172

\section{Figures}




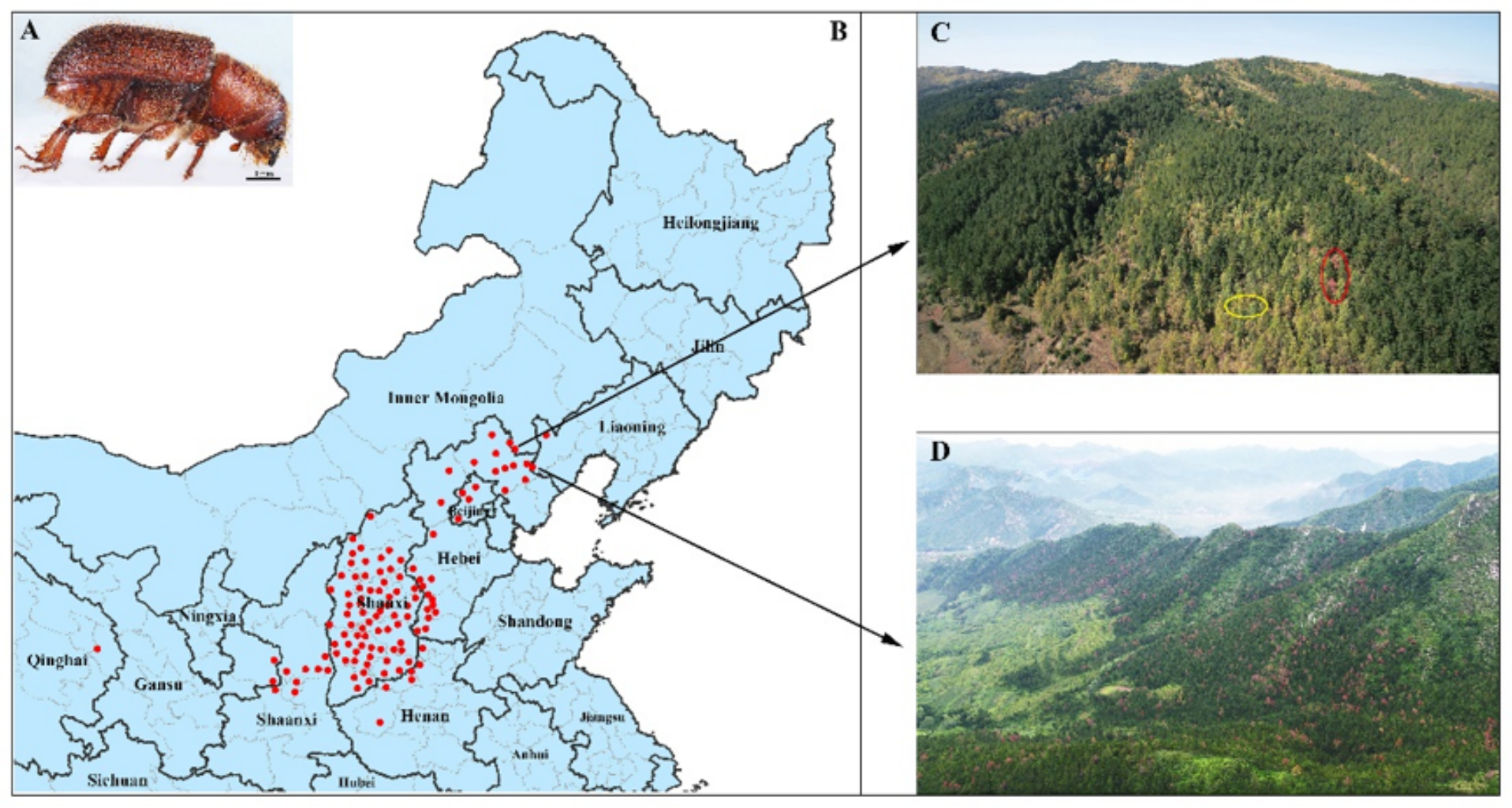

Figure 1

The forests in the early and middle stages of RTB invasion. a Adult RTB. $b$ Areas in North China that have been invaded by RTB. Red dots indicate individual RTB invaded areas at the city level. c The Helihe area that is in the early stage of RTB invasion. The yellow trees (in the yellow circle) are discolored larch (in autumn), which are not caused by RTB invasion. The two Chinese pines with a red crown (in the red circle) are the result of RTB attack. $d$ The Dahebei area that is in the middle stage of RTB outbreak. Note: The designations employed and the presentation of the material on this map do not imply the expression of any opinion whatsoever on the part of Research Square concerning the legal status of any country, territory, city or area or of its authorities, or concerning the delimitation of its frontiers or boundaries. This map has been provided by the authors. 


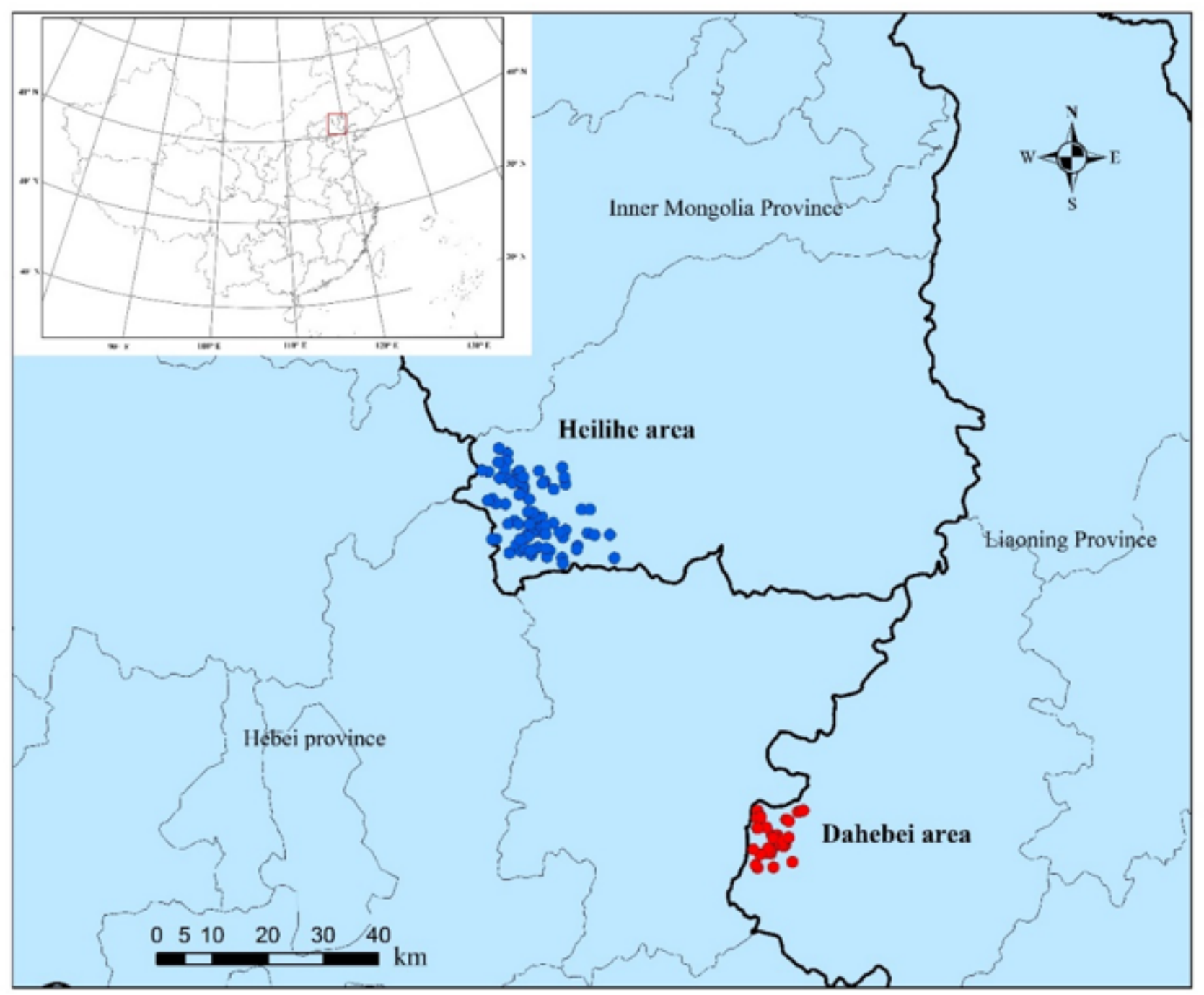

Figure 2

Location of the 79 sample plots (blue dots) in the Heilie area and 32 sample plots (blue dots) in the Dahebei area. Note: The designations employed and the presentation of the material on this map do not imply the expression of any opinion whatsoever on the part of Research Square concerning the legal status of any country, territory, city or area or of its authorities, or concerning the delimitation of its frontiers or boundaries. This map has been provided by the authors. 


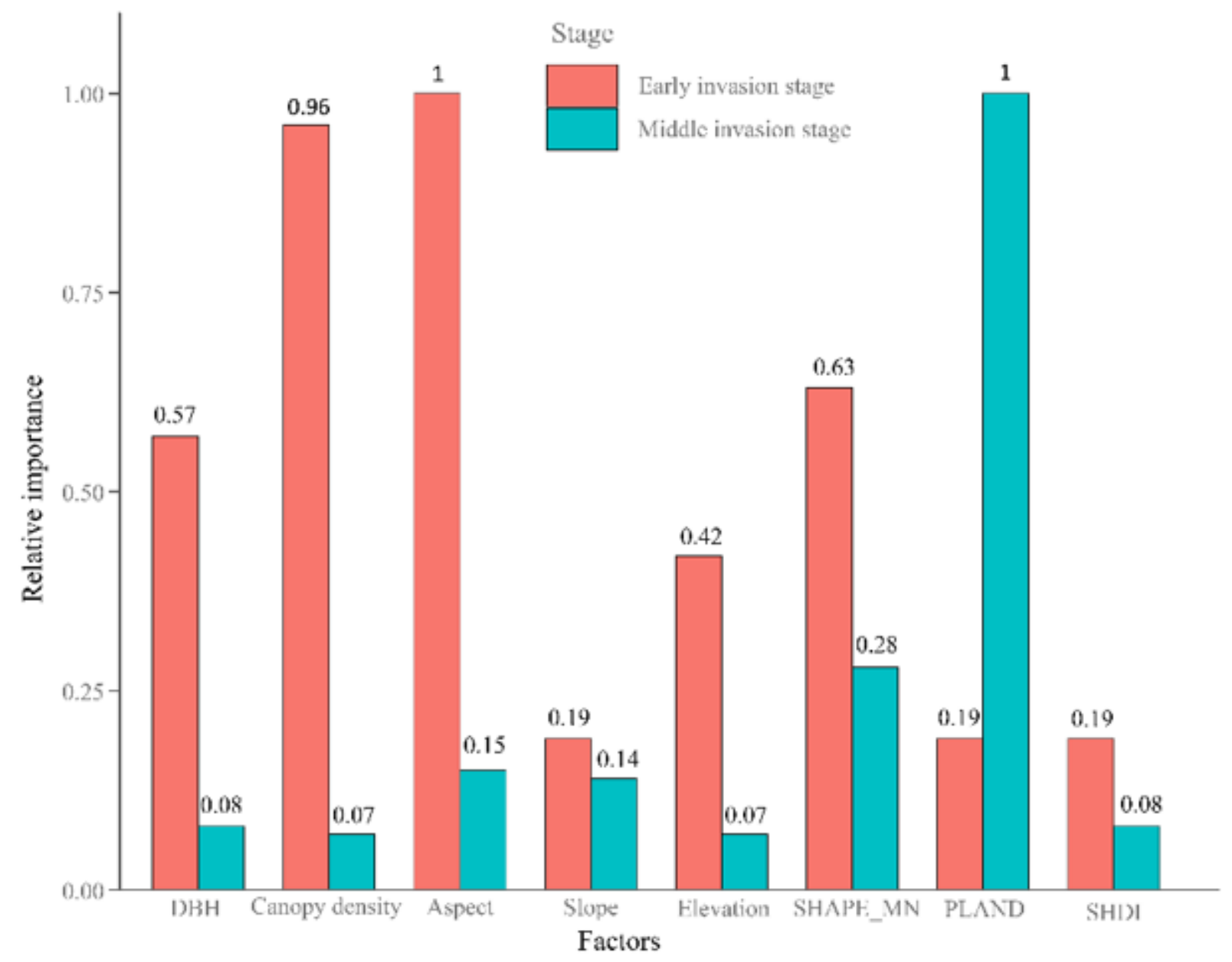

Figure 3

Relative importance of landscape- and stand-level factors in different stages of RTB outbreak. The relative importance is the sum of the Akaike weights associated with each variable in the models in the top model set.
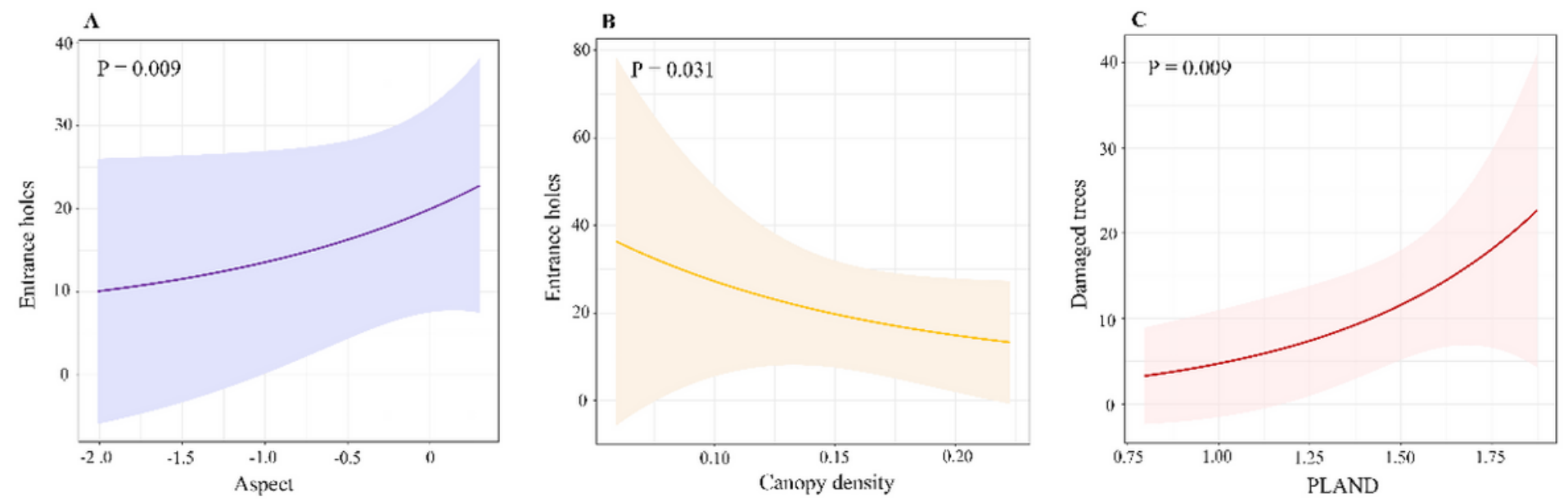

Figure 4 
Model-averaged predictions and standard errors showing the response of to RTB damage to a Aspect ( $\mathrm{x}$ axis means the change from northeast to southwest), b Canopy density and c PLAND. P value was the parameter estimation based on model average and SEs (see Table 2)
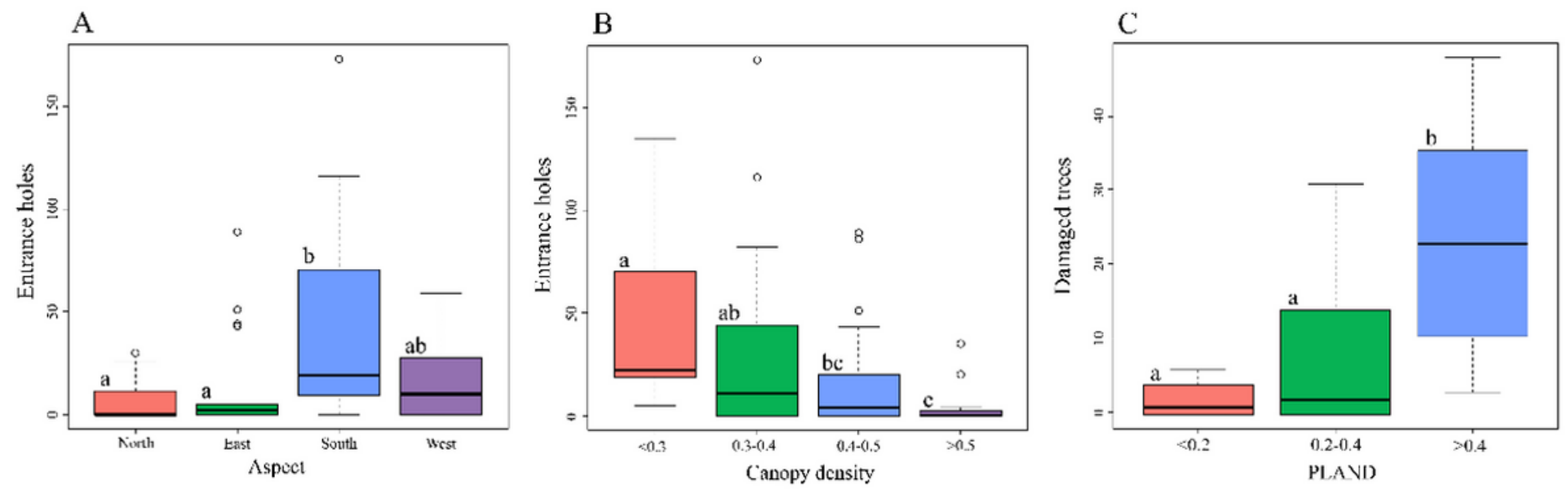

Figure 5

The numbers of RTB entrance holes and damaged trees as important variables. a Aspect $(\mathrm{df}=15,17,15$, and 23 , from left to right). b Canopy density ( $d f=7,21,33$, and 15 , from left to right). c PLAND ( $d f=4,17$, and 11 , from left to right).

\section{Supplementary Files}

This is a list of supplementary files associated with this preprint. Click to download.

- Supplementaryfile.docx 